Portland State University

PDXScholar

Systems Science Faculty Publications and

Presentations

Systems Science

$6-5-2020$

\title{
Words and Diagrams about Rosenzweig's Star
}

Martin Zwick

Portland State University, zwick@pdx.edu

Follow this and additional works at: https://pdxscholar.library.pdx.edu/sysc_fac

Part of the Jewish Studies Commons

Let us know how access to this document benefits you.

\section{Citation Details}

Zwick, M. (2020). Words and Diagrams about Rosenzweig's Star. Naharaim, 14(1), 5-33.

This Post-Print is brought to you for free and open access. It has been accepted for inclusion in Systems Science Faculty Publications and Presentations by an authorized administrator of PDXScholar. Please contact us if we can make this document more accessible: pdxscholar@pdx.edu. 


\title{
Words and Diagrams about Rosenzweig's Star ${ }^{1}$
}

\author{
Martin Zwick \\ Portland State University, Portland OR 97207 USA \\ zwick@pdx.edu \\ $4 / 11 / 2020$
}

\begin{abstract}
This article explores aspects of Rosenzweig's Star of Redemption from the perspective of systems theory. Mosès, Pollock, and others have noted the systematic character of the Star. While "systematic" does not mean "systems theoretic," the philosophical theology of the Star encompasses ideas that are salient in systems theory. The Magen David star to which the title refers, and which deeply structures Rosenzweig's thought, fits the classic definition of "system" - a set of elements (God, World, Human) and relations between the elements (Creation, Revelation, Redemption). The Yes and No of the elements and their reversals illustrate the bridging of element and relation with the third category of "attribute," a notion also central to the definition of "system." In the diachronics of "the All," the relations actualize what is only potential in the elements in their primordial state and thus remedy the incompleteness of these elements, fusing them into an integrated whole. Incompleteness is a major theme of systems theory, which also explicitly examines the relations between wholes and parts and offers a formal framework for clearly expressing such fusions.

In this article, the systems character of Parts I \& II of the Star is explored through extensive use of diagrams; a systems exploration of Part III is left for future work. Remarkably, given its highly architectonic character, diagrams are absent in Rosenzweig's book, except for the triangle of elements, the triangle of relations, and the hexadic star, which are presented on the opening page of each part of the book. While structures can be explicated entirely in words, diagrams are a visual medium of communication that supplements words and supports a nonverbal understanding that structures both thought and experience.
\end{abstract}

\section{Key words}

Franz Rosenzweig, Star of Redemption, systems theory, metaphysics, theology, diagrams, Creation, Revelation, Redemption, elements, relations, attributes

\section{Introduction}

As Mosès, Samuelson, Pollock and others have argued, ${ }^{2}$ Franz Rosenzweig was committed to systematic thought and in The Star of Redemption developed a highly structured

\footnotetext{
${ }^{1}$ Naharaim (2020); 14(1): 5-33. https://doi.og/10.1515/naha-2019-0019. This article is an expanded version of a paper titled "Diachronics of Redemption," presented at Back to Redemption, an International Rosenzweig Society Conference, Feb. 17-20, 2019, Jerusalem, Israel.

${ }^{2}$ Stephanie Mosès, System and Revelation: The Philosophy of Franz Rosenzweig, trans. Catherine Tihanyi (Detroit: Wayne State University Press, 1992); Norbert A. Samuelson, A User's Guide to Franz Rosenzweig (Abingdon-on-Thames: Routledge, 1999); Benjamin Pollock, Franz Rosenzweig and the Systematic Task of Philosophy (New York: Cambridge University Press, 2009a).
} 
philosophical theology. ${ }^{3}$ In this article I argue that Rosenzweig's thought has affinities with systems theory. While being systematic is not the same as being systems theoretic, systematicity in any field of knowledge invariably requires ideas that are applicable to many phenomena outside that field. Systems theory has been characterized as an attempt to construct an "exact and scientific metaphysics. ${ }^{4}$ Viewed in this way, it is not a theory per se, but an intellectual project, encompassing an ensemble of theories such as graph theory, information theory, nonlinear dynamics, fractal geometry, etc., and the Star makes use of many ideas from such theories. It is not surprising that a philosophical-theological work should have (partially) a systems theoretic character, since systems ideas are widely used not only in the natural and social sciences, but also in the humanities, including philosophy and religion. Works by Deutsch, Luhmann, Macy, Kauffman, Zwick, and Locker are a few examples of the literature in which systems ideas have been used to address religious themes. ${ }^{5}$

Being systematic, the Star is highly structured, and this structure is explicit. Most philosophies, if they have a discernible structure at all, have a hidden endoskeleton. The Star, by contrast, has a visible exoskeleton. It is possible to depict this exoskeleton as a diagram, and diagrams are part of any exposition of systems ideas, so this presentation of the systems ideas salient in the Star will make extensive use of diagrams. The general question of the role of diagrams in works of philosophy and theology is a timely one, given the new interest in diagrams in Kabbalah studies. ${ }^{6}$ Although many diagrams exist in the Kabbalistic literature, they were devalued by Scholem, who regarded them as "confusing more than clarifying."7 The situation with Rosenzweig is the opposite. Rosenzweig did not present any diagrams in the Star beyond a triangle of three elements, a triangle of three relations, and the Magen David hexad that links these triangles together (Figure 1).

\footnotetext{
${ }^{3}$ Franz Rosenzweig, The Star of Redemption, trans. Barbara E. Galli (Madison: University of Wisconsin Press, 2005).

${ }^{4}$ Mario Bunge, Method, Model, and Matter (Boston: D. Reidel, 1973), “Chapter 8. Is Scientific Metaphysics Possible?”

${ }^{5}$ Karl Deutsch, The Nerves of Government: Models of Political Communication and Control (New York: Free Press, 1963); Niklas Luhmann, A Systems Theory of Religion. ed. André Kieserling. trans. David A. Brenner with Adrian Hermann (Palo Alto: Stanford University Press, 2014); Joanna Macy, Mutual Causality in Buddhism and General Systems Theory (Albany: SUNY Press, 1991); Stuart Kauffman, Reinventing the Sacred: A New View of Science, Reason, and Religion (New York: Basic Books, 2008); Martin Zwick, "Systems Metaphysics: A Bridge from Science to Religion,” Metanexus, June 24, 2007. https://www.metanexus.net/systems-metaphysics-bridge-science-religion/; Markus Locker, ed., Systems Theory and Theology: The Living Interplay between Science and Religion (Eugene: Pickwick Publications, 2010).

${ }^{6}$ Some recent studies of diagrams in Kabbalah are Marla Segol, Image in Medieval Kabbalah: The Texts, Commentaries, and Diagrams of the Sefer Yetsirah (New York: Palgrave Macmillan, 2012); Giulio Busi, "Beyond the Burden of Idealism: For a New Appreciation of the Visual Lore in the Kabbalah," in Kabbalah and Modernity: Interpretations, Transformations, Adaptations. ed. Boaz Huss (Leiden: Brill, 2011). https://doi.org/10.1163/ej.9789004182844.i-436; J. H. Chajes, "Kabbalistic Diagram as Epistemic Image,” Peamim 150 (2017): 235-288.

${ }^{7}$ The quote is from J. H. Chajes, "Kabbalistic diagrams in the British Library’s Margoliouth Catalog.” 2016. https://www.bl.uk/hebrew-manuscripts/articles/kabbalistic-diagrams-in-the-british-librarysmargoliouth-catalogue.
} 
Figure 1. Diagrams in the Star

Each diagram introduces a part of the book. At the beginning of the book all three diagrams are displayed on a single page arranged vertically. The points on the triangles and the star are unlabeled.

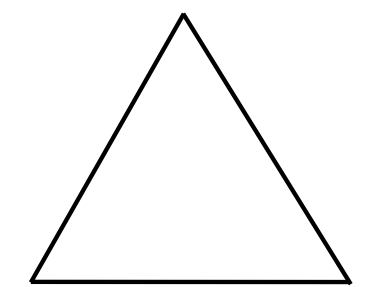

(a) PART ONE

THE ELEMENTS

or

THE EVERLASTING

PRIMORDIAL WORLD

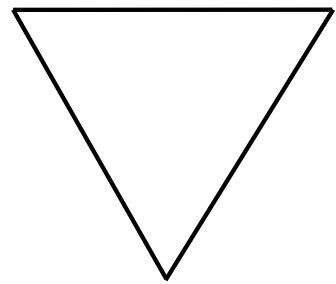

(b) PART TWO

THE PATH

or

THE EVER RENEWED

WORLD

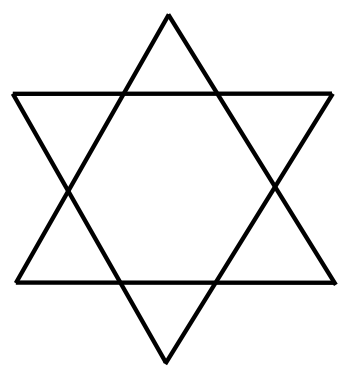

(c) PART THREE

THE CONFIGURATION

or

THE ETERNAL SUPRAWORLD

Nevertheless, even this minimal use of diagrams evoked a Scholemian dismissal by Gordon, who stated "[s]ome readers may indeed find the star configuration almost too clever; there is a touch of wizardry about it, a Kabbalistic symbol-mongering that a philosopher of greater prudence, though perhaps less imagination, might have thought best to avoid."8

Edmund Wilson wrote that metaphysics is the "poetry of imaginative people who think in abstractions instead of in images." 9 The "abstractions" he referred to were verbal concepts, and the "images" he spoke of were visual representations. Diagrams are a fusion of both; they are abstract images. The discussion below of the systems theoretic character of Parts I \& II of the Star will introduce additional diagrams. The many possible configurations of a diagram are visually what Kabbalistic combinations of letters are verbally; moreover, a diagram can "be surveyed with one glance as an aesthetic whole," ${ }^{10}$ while narrative, like music, can convey a whole only in time. Rosenzweig imagined a "telescope and spectroscope"11 that would facilitate intuition via mystical vision. Diagrams do not reach this height, but they can be grasped by intellectual vision. In the teaching and doing of mathematics and science, the use of diagrams along with words is commonplace; arguably, in such contexts it even qualifies as "speech thinking.” Or, to borrow a metaphor from Levinas, diagrams translate from Hebrew into Greek.

\section{System}

\subsection{Elements and relations}

Figure 2(a) shows Rosenzweig’s star. Figure 2(b) shows how a systems theorist might represent it.

${ }^{8}$ Peter Gordon, Rosenzweig and Heidegger: Between Judaism and German Philosophy (Oakland: University of California Press, 2003), 123.

${ }^{9}$ Edmund Wilson, To the Finland Station (New York: Doubleday, 1940), 224.

${ }^{10}$ Rosenzweig, 210

${ }^{11}$ Rosenzweig, 313. 
Figure 2. Two representations of Rosenzweig's star

(a) shows the conventional Davidic hexad.

(b) shows a synchronic systems theoretic representation.

Elements are shown as solid lines; relations and the ways they link elements as dashed lines.

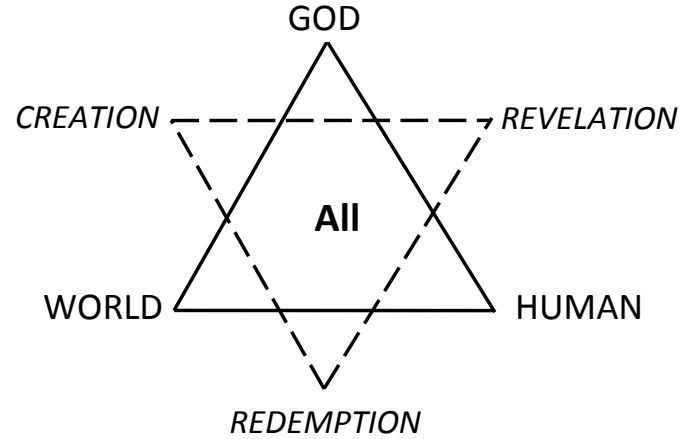

(a)

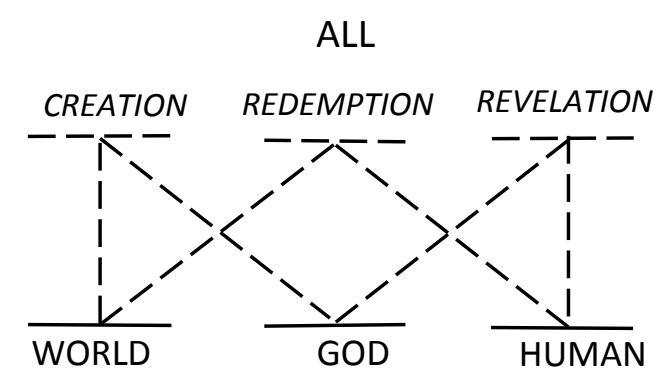

(b)

A "system" is a set of elements and relations linking the elements. ${ }^{12}$ This definition is graph theoretic, specifying nodes (elements) and links between nodes (relations). However, in a purely graph theoretic representation only the connectivity of the elements matters, not their spatial locations. The Gestalt theorist Andreas Angyal argued, however, that the spatial aspects of systems are also important. ${ }^{13}$ This is the case for the two representations shown in Figure 2, where the spatial locations of both the elements and the relations carry meaning.

Rosenzweig's star is a system. It has three elements: God, World, and Human. Reality is "shattered" in that three elements exist; not two, not one. It also has three relations. The relation between God and World is Creation; the relation between God and Human is Revelation; the relation between Human and World is Redemption. There is no systems theoretic reason for there to be exactly three elements and three relations, or for them to have specific identities, but the star is clearly a system in a systems theoretic sense.

Relations are to elements as form is to matter. While systems theory accords matter and form equal ontological status, it privileges form over matter to compensate for the emphasis on matter in scientific explanation. It thus embraces a Platonic conception of form as above matter, as reflected in Figure 2(b), while also encompassing an Aristotelian view of matter and form as equal and intertwined. For Rosenzweig, elements are primordial, but relations generate "the All," so elements and relations might be viewed as equal; this is also suggested graphically by the symmetry of the star. Still, there is a sense in which Rosenzweig privileges relations over elements. Mosès writes: "But, in reality it is relations that are primary: the lived experiences of Creation, Revelation, and Redemption express the reality of God, of the world, and of man, and not the other way around. This priority of relations over substance, of movement over being.... are symbolized by and."14

\footnotetext{
${ }^{12}$ Arthur D Hall and Robert E. Fagen, “Definition of System.” General Systems 1 (1956): 18-28.

${ }^{13}$ Andras Angyal, “The Structure of Wholes,” Philosophy of Science 6, no.1 (1939): 25-37.

${ }^{14}$ Mosès, 141; emphasis in original.
} 
In the systems perspective, elements and relations are two sides of the same coin. For example, an atom looking inward is form (a relation between nucleus and electrons) but an atom looking outward is matter (an element participating in external relations with other elements to constitute a molecule). Mathematically, elements and relations can both be defined as sets, and all relations in a system can be subsumed within a single relation. The notion of system is thus recursive: every element is a system and every system is an element. Recursion is not an explicit feature of Rosenzweig's scheme, although he sees World as a comprised of particulars, each of which could be viewed as a system. ${ }^{15}$

But Rosenzweig's system is radically different from systems normally considered by systems theorists. As Pollock has argued, while Rosenzweig rejects the totalism of German Idealism, he takes up the "systematic task of philosophy" which was its ambition. ${ }^{16}$ Although reality is fractured into three elements and its unification deferred to eternity, Rosenzweig's All is still totalistic. Systems theory, however, aims at describing partial wholes that do not embrace everything because they exist within environments. It focuses on systems that are ubiquitous, and thus is uninterested in a fundamental top - a totalistic All having no environment - or a fundamental bottom - an elemental having no parts. This being said, systems theory generally attempts a "crude look at the whole," 17 which is certainly in the spirit of systematic philosophy.

Figure 3. A diachronic systems representation of the star

ALL

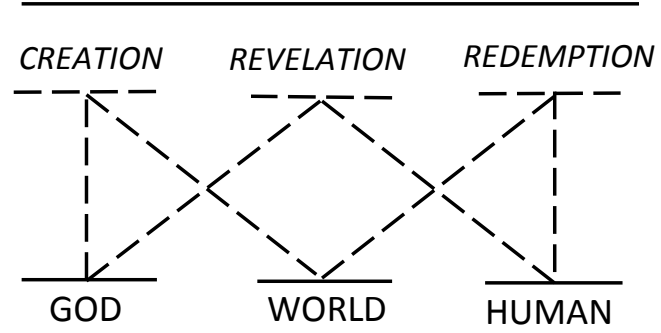

In the synchronic systems representation of Figure 2(b), World and Creation are on the left, God and Redemption are in the center, and Human and Revelation on the right, analogous to their positions in the star. A diachronic systems representation is shown in Figure 3; reading from left to right, the temporal order of elements is God, World, and Human; the temporal order of relations is Creation, Revelation, and Redemption. All this is from the Human perspective in which God, World, and Human are equal elements. The figure depicts the completion of the All, but for Rosenzweig diachronics proceeds in three stages and its completion is only anticipated but not actualized. A systems theoretic representation of these stages is given below in Figure 8 . To arrive at this representation, the definition of "system" must first be augmented to include the notion of "attributes"; this is done in the next two sections.

\footnotetext{
${ }^{15}$ Also, a human being is a whole having parts, and in Kabbalah the Sefirot constitute an internal structure for God (or emanations of God), but these whole-part relations are not taken up by Rosenzweig.

${ }^{16}$ Pollock, op cit.

${ }^{17}$ This characterization of the systems project is from Murray Gell-Mann, The Quark and the Jaguar: Adventures in the Simple and the Complex (New York: W. H. Freeman \& Co, 1994), xiv. It is also part of the title of the book by John H. Miller, A Crude Look at the Whole: The Science of Complex Systems in Business, Life, and Society (New York: Basic Books, 2016)
} 


\subsection{Attributes}

A more complete notion of "system" reflects the idea that elements are related to one another not directly but via attributes. ${ }^{18}$ Although commonly attributes are viewed as belonging to elements, attributes can belong either to elements or to relations, or more generally to both. So, a more complete definition of "system" is a set of elements, attributes, and relations, where elements are related to one another through attributes. This triadic definition of "system" is illustrated by Figure 4, in which relation $\mathrm{AB}^{\prime}$ links elements e and $\mathrm{e}^{\prime}$ via attributes $\mathrm{A}$ and $\mathrm{B}^{\prime}$.

Figure 4. Attributes mediate between elements and relations

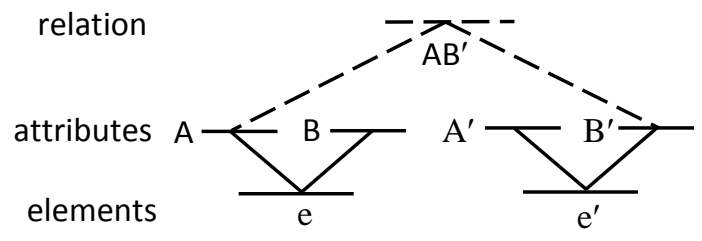

Each of Rosenzweig's elements has two attributes, Sache, "substance,” and Tat, "act," depicted in Figure 5(a). These attributes, also called 'Yes' and 'No,' are bound together by an 'And. ${ }^{19}$ Yes and No are equal; the No is not an antithesis to a Yes as thesis. Yes and No polarities of attributes reverse when elements enter into relation with one another.

Figure 5. Attributes belong to both elements \& relations

(a) A Rosenzweig element (e) has attributes $\boldsymbol{S}$ and $\boldsymbol{T}$ (Sache, substance and $\boldsymbol{T a t}$, act).

(b) A relation (r) can also bind together attributes.

(c) A structure-function representation of the $\boldsymbol{S}$ - $\boldsymbol{T}$ dyad.

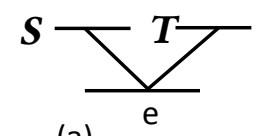

(a)

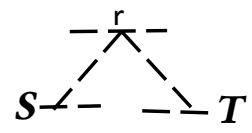

(b)

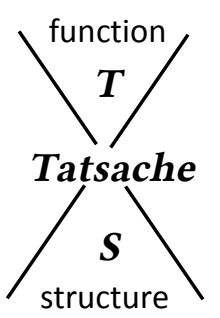

(c)

structure

An element with its attributes is Tatsache, a fusion of substance and act which means "fact." Since attributes also belong to relations, as depicted in Figure 5(b), a relation with its attributes is also fact. The systems view that elements and relations are two sides of the same coin resembles Rosenzweig's view that both elements and relations are facts. The Sache-Tat dyad also resembles the systems theoretic dyad of structure-function or being-behaving or essence-exchange $^{20}$ and thus can be represented as the double cone of Figure 5(c). The lower

\footnotetext{
${ }^{18}$ Hall and Fagen, op cit.

${ }^{19}$ From a systems perspective, the element itself, which binds together attributes, is such an And. Rosenzweig sees an attribute as a free-standing adjective, joined by the thing that bears it, the thing itself being a "dark abstraction," 139. Systems theoretically, a thing is an element, defined by George Klir in Architecture of Systems Problem Solving (New York: Plenum Press, 1985), as an "auxiliary support variable," an abstract index.

20 "Structure" here means internal order; "function" here does not connote purpose, just participation in an external order. The "being-behaving” formulation comes from Ralph Gerard, "Concepts and Principles of Biology.” Behavioral Science 3 (1958): 95-102; the “essence-exchange” formulation comes from Hugo
} 
cone represents internal substance, i.e., structure; the upper cone represents external act, i.e., function; the two cones together are Tatsache.

All three of Rosenzweig's elements have these two generic attributes, but substance and act for each element are different. The attributes of the elements in the primordial condition are shown in Figure 6, where Yes and No values are shown as ' $y$ ' and ' $n$,' respectively. An attribute carried by an isolated element is pure potential, becoming actualized only when the element is involved in an external relation. ${ }^{21}$ And an element whose attributes are merely potential is viewed by Rosenzweig as inherently unstable, susceptible to unraveling and dissolving into Nothing. $^{22}$

Figure 6. The attributes of Rosenzweig's elements in isolation For each element, y (Yes) and n (No) are Sache (substance) and Tat (act).
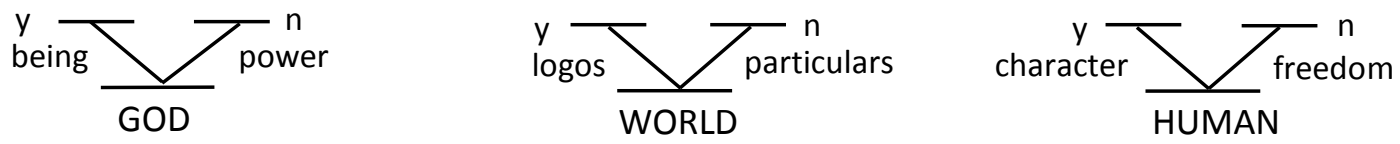

\subsection{Incompleteness, inconsistency, reversal}

Since attributes are carried by both elements and relations, there arises the possibility that elements might have attributes not involved in any relation, or that relations might have attributes not shared by any element. This is shown in above Figure 4 where attributes B and $\mathrm{A}^{\prime}$ are not involved in any relation and are thus only potential. An attribute which is potential and not actual can be regarded as a manifestation of incompleteness. There is also the possibility of a mismatch between the value of the attribute called for by the relation and the value it has for the element; this can be regarded as a manifestation of inconsistency. "Incompleteness" and “inconsistency” here do not have Gödel's technical meanings. ${ }^{23}$ If these terms are interpreted more broadly, one can say that beyond some minimum level of complexity systems generally suffer from incompleteness and/or inconsistency. ${ }^{24}$

Figure 7 adds to above Figure 4 a depiction of the inconsistency that manifests in a mismatch between the value of attribute $A$ as carried by element e and its value as carried by relation $\mathrm{AB}^{\prime}$. These are shown as parallel horizontal lines; the lower solid line is the value (y)

duCoudray, Mentius Nuncius: A Schema for Psychology. 2011. lulu.com. There is a similar Chinese dyad, namely ti-yong, translated as substance-function or essence-function; see Chan Wing-tsit, A Source Book in Chinese Philosophy (Princeton: Princeton University Press, 1969).

${ }^{21}$ Although Rosenzweig says (140), “Before his emergence from himself, God cannot have any attributes at all," and suggests that attributes come to exist only when the elements enter into external relations, the notion of attribute must still apply to the primordial state (which Rosenzweig also indicates in other places), because otherwise attributes could not be said to reverse when elements enter into relations.

${ }^{22}$ The instability of elements whose attributes are only potential is an idea of Rosenzweig's, not a recognizable systems theoretic notion, but a scientific analog of such instability is illustrated by an unfilled ecological niche which can easily disappear if the ecosystem changes.

${ }^{23}$ An accessible presentation of Gödel's work is offered by Ernest Nagel and James R. Newman, Gödel's Proof (New York: New York University Press, 1960).

${ }^{24}$ Martin Zwick, “Incompleteness, Negation, Hazard: On the Precariousness of Systems,” Nature and System 6 (1984): 33-42. 
carried by e; the upper dashed line is the value $(n)$ carried by $A^{\prime}$. There is a similar mismatch between the value $(n)$ of attribute $B^{\prime}$ as carried by $e^{\prime}$ and its value $(y)$ as carried by $A^{\prime}$.

Figure 7. Attribute incompleteness and inconsistency (reversal)

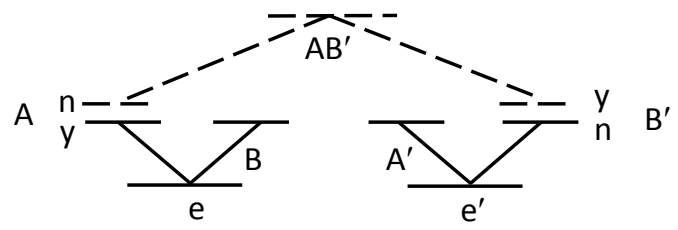

The standard illustration of inconsistency in the sense of attribute mismatch is "a round peg in a square hole,” a topic explored in Gestalt psychology, which contributed to the development of systems theory. Rosenzweig's idea that attribute reversals are required for elements to enter into relations can be diagrammed in the same way as gestalt mismatches: the double values of attributes A and B' in Figure 7 can be interpreted as polarity reversals of these attributes when elements enter into relation. The straightforward interpretation of such reversals is that the original polarities (lower solid lines) are replaced by their opposites (upper dashed lines). Thus, in Figure 7 for A, Yes is replaced by No, and for B', No is replaced by Yes. But an alternative view is to regard reversal as supplementation rather than replacement: Yes would be the value of the attribute as carried by element e; No, its additional value as carried by relation $\mathrm{AB}^{\prime}$. If reversal is viewed as supplementation, an attribute would retain both values.

\section{Diachronics}

\subsection{Creation, Revelation, Redemption}

With this expanded definition of "system" and the notions of incompleteness, inconsistency, and reversal, the diachronics of the Star can be represented in systems theoretic terms, as in Figure 8. In Creation (stage1, the lowest stage in this figure) the incompleteness of God's attribute of power and World's attribute of logos are resolved by reversals that relate God and World. Power, the No for God as isolated, becomes Yes for God as creator; logos, the Yes for World as isolated becomes No for World as created; the reversed attributes linked by Creation are a new fact, Tatsache. This leaves the being attribute of God, the particulars attribute of World, and both Human attributes uninvolved in any relation.

Creation is supplemented by Revelation (stage2, the middle stage in the figure), which connects God and Human. The infinite being of God reverses from Yes to No, and the freedom of the Human reverses from No to Yes. The reversed attributes, linked by Revelation, constitute a second new fact. After Revelation, both attributes of God have reversed, and their potentials are realized. But if reversal is viewed as replacement, the binding of these two attributes previously accomplished by an 'And' internal to God is disrupted, so the gain of completeness in God's attributes is diminished by their loss of unity. 
Figure 8. The diachronics of Redemption

The diagram should be read from the bottom up.
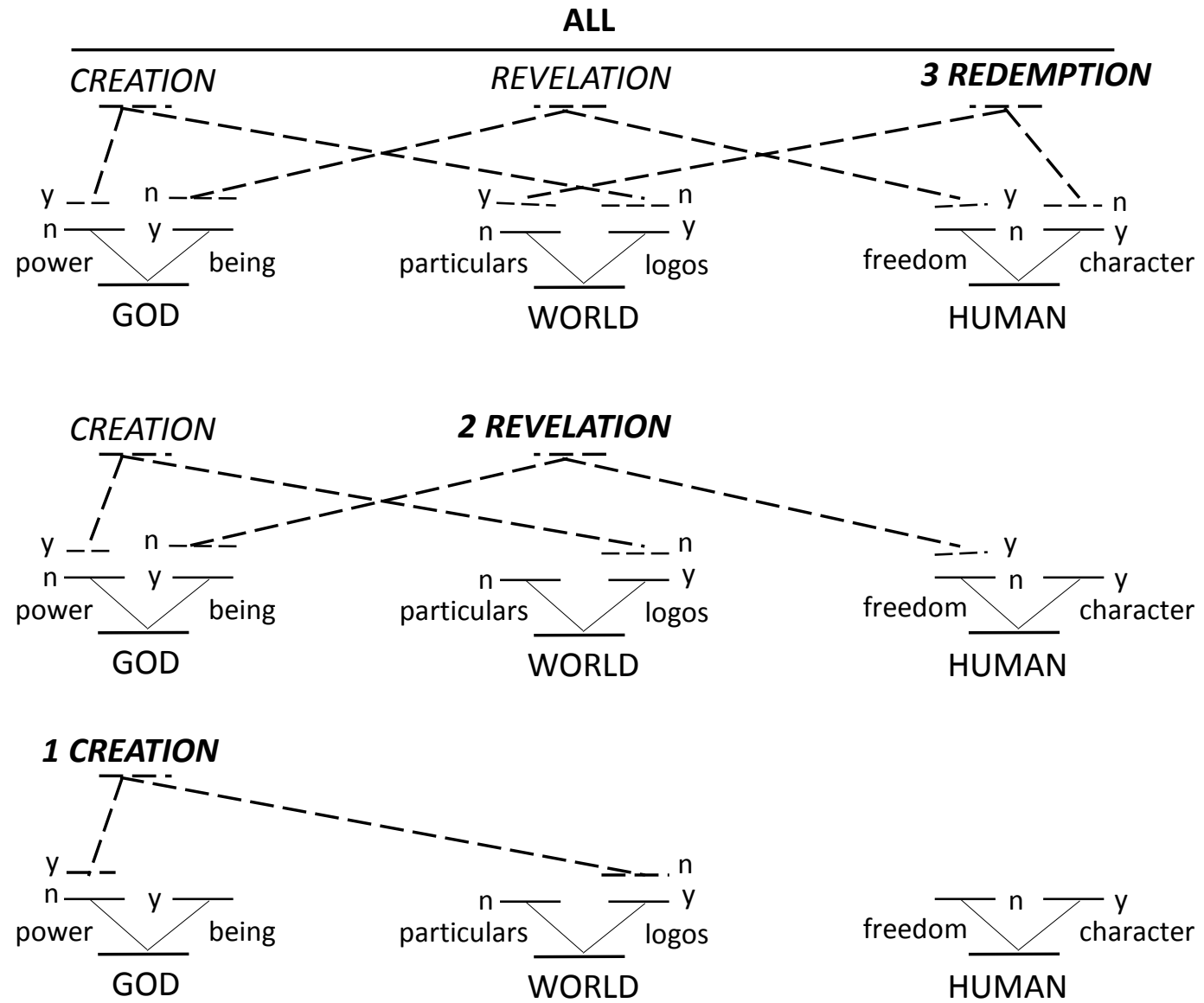

TIME

Moreover, after Revelation, World and Human are still incomplete, since each has an attribute not involved in any relation. The system can still unravel. Finally, in Redemption (stage3, the uppermost stage in Fig. 8), the character of Human reverses from Yes to No and the particulars of World reverse from No to Yes, allowing Human and World to enter into relation. With the addition of this relation, and in the view of reversal as replacement, the unity of God's attributes is finally regained, albeit only indirectly. Incompleteness is fully remedied. When all three elements enter into relation with one other their attributes become actual, the triad of elements and the triad of relations are locked together, the circuit connecting the elements is closed, and a stable system of the All is generated.

As Figure 8 demonstrates, the open circuit of stage2 is closed in stage3. Mosès describes this as follows:

In the logical formalism of the Star, the same idea was expressed in the following way: the Yes of God to the world (that is, Creation) prolongs itself in the Yes of the world to man (profusion of life). God's self-negation for man's benefit (Revelation) is prolonged through man's self-negation for the benefit of the world (that is, the love of neighbor). The encounter of the world as affirmation and of man as negation (an encounter that is the Redemption) is 
at the same time that of the yes and the no of God himself and is formally translated through the conjunction and. ${ }^{25}$

Figure 9(a) below shows this "prolongation" of the Yes and the No of God (Yes in solid lines, No in dashed lines, neither bold) until Redemption by linking Human and World (bold solid and dashed lines), indirectly links these two attributes of God together. Rosenzweig describes this indirect linkage as follows: ${ }^{26}$ "In redemption, the great And caps the arch of the universe." Only in Redemption is the unity of the attributes of God, broken when God entered into relations with World and Human, reestablished, as shown in Figure 9(a). And just as Redemption is the And that links the Yes of Creation and the No of Revelation and brings unity to God, so too Revelation is the And that links the Yes of Redemption and the No of Creation and brings unity to World, as shown in Figure 9(b). Also, Creation is the And that links the Yes of Revelation and the No of Redemption and brings unity to Human, as shown in Figure 9(c).

Figure 9. The relations indirectly unite the attributes of the elements The diagram should be read from the bottom up. The two attributes of each element in bold are united by the relations in bold. Solid vs dashed lines follow Yes and No, respectively. Attributes shown are reversed.

(a)

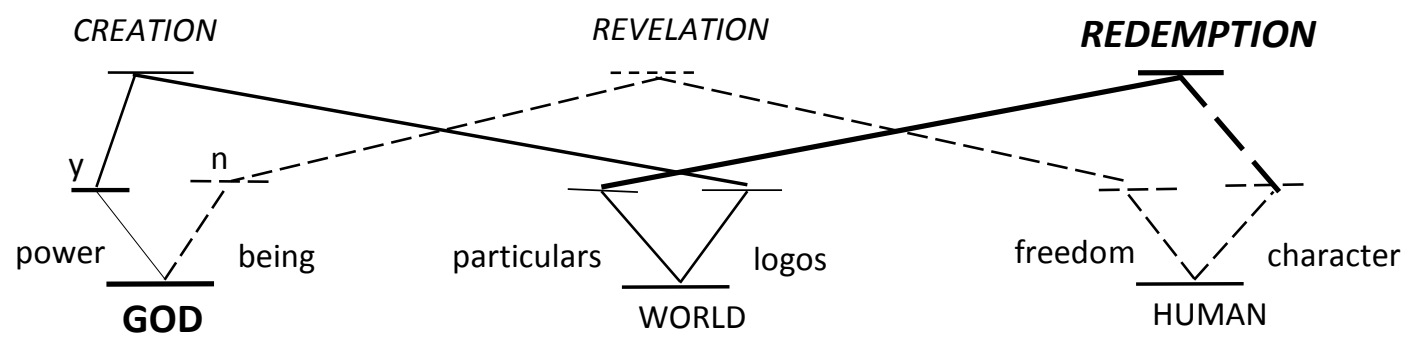

(b)

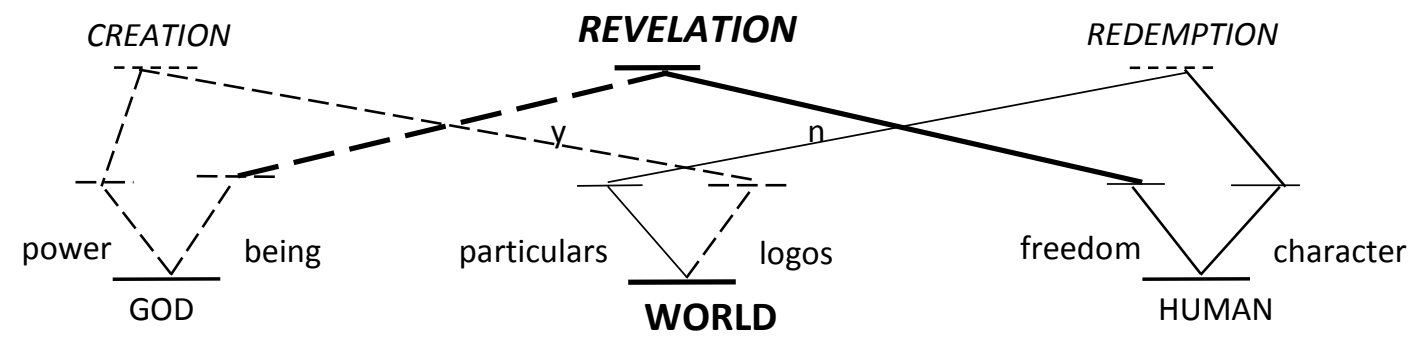

(c)

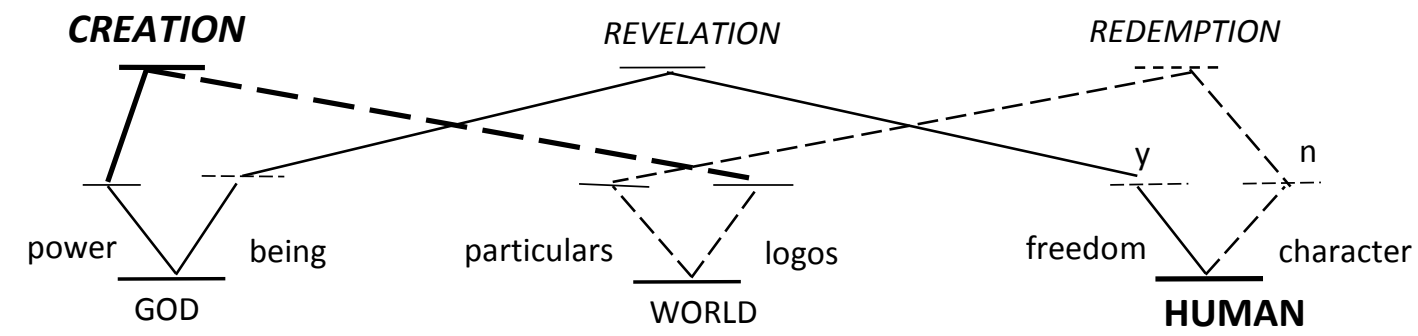

Figure 9(a) shows Redemption as an indirect relation between the Yes of Creation (the path of solid lines) and the No of Revelation (the path of dashed lines). Similarly, Figure 9(b)

\footnotetext{
${ }^{25}$ Mosès, 139; emphasis on "prolongs" added.

${ }^{26}$ Rosenzweig, 246.
} 
shows Revelation as an indirect relation between the Yes of Redemption and the No of Creation; and Figure 9(c) shows Creation as an indirect relation between the Yes of Revelation and the No of Redemption. These indirect relations are summarized in Figure 10. A relation can join not only elements but also relations, since both carry attributes, and both for Rosenzweig are facts.

Figure 10. Each relation unites the other two relations

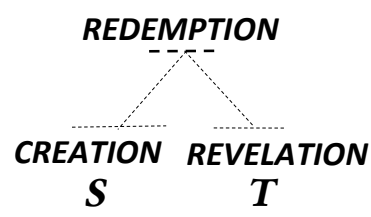

(a)

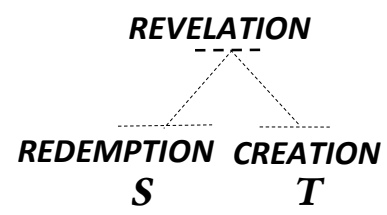

(b)

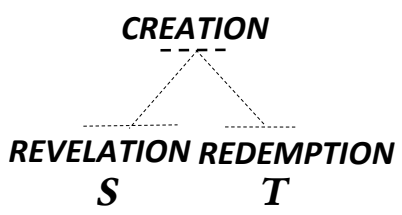

(c)

By joining together the other two relations, Redemption unifies the attributes of God; Revelation unifies the attributes of World; Creation unifies the attributes of Human (Figure 11). Creation unifies Human by joining Revelation and Redemption: Rosenzweig writes, "And how else could he know himself to be loved by God exactly as the same one whom he himself loves in the neighbor, than because God has created in his image that which is common between him and his neighbor." ${ }^{27}$ Revelation unifies World by joining Creation and Redemption, because Revelation is "the assurance given to the world for its Redemption." ${ }^{28}$ As for the unification of God in Redemption, Rosenzweig writes, "God [is] redeemed from all the work of the six days of Creation and from all loving anxiety about our poor soul."29

Figure 11. Each relation unifies its opposite element in the star

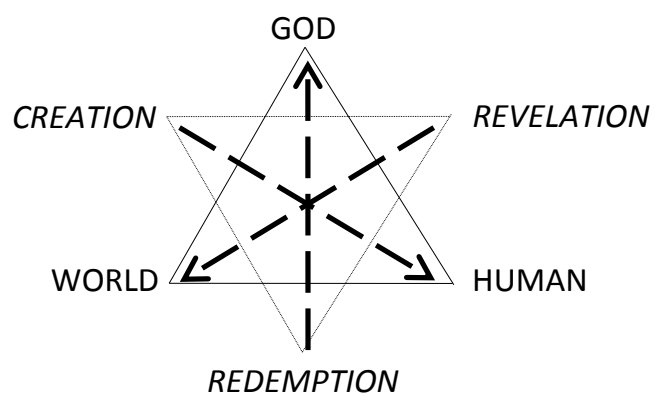

\subsection{Reversals as replacements or supplementation}

In the discussion above, reversals have been viewed as replacements of the primordial polarities. In this view, the binding of Sache and Tat for each element, which was originally endogenous when the element was isolated, is fully exogenous after Creation, Revelation, and Redemption. This is consistent with Idealism's doctrine of holism, in which everything is what it is by participation in a larger whole. However, from the perspective of systems theory this doctrine is problematic. It is one thing to hold that elements are constituted not only internally but also externally; it is quite another to hold that elements are constituted solely by external relations. The very notion of "system" implies the existence of some internal order that

\footnotetext{
${ }^{27}$ Rosenzweig, 278.

${ }^{28}$ Rosenzweig, 279.

${ }^{29}$ Rosenzweig, 280.
} 
distinguishes it from an unorganized aggregate, an order which is therefore constitutive. Since the notion of "system" is recursive, an element is itself a system, so to view reversal as replacement and take elements as constituted solely externally is, from the perspective of systems theory, implausible. ${ }^{30}$ But exogenous binding of attributes might be viewed as being in addition to endogenous binding, with attributes bound together not only indirectly and externally by the relations that link the elements, but also directly and internally by the And of elements taken as isolated. If unreversed and reversed states of the attributes are promise and fulfillment, or potential and actual, fulfillment does not nullify promise, and actual does not nullify potential. Figure 8 (above) can be viewed in this way, with double lines for attributes indicating binding that is both endogenous (below by elements) and exogenous (above by relations).

This interpretation of reversal as supplementation and not replacement may be a deviation from Rosenzweig's system. Or, perhaps supplementation and not replacement is what Rosenzweig in fact intended. Romanticism - which colored Rosenzweig's thought - often encompassed the view that "[a] given quality is potentially, and then actually, its opposite, without ceasing to be what it was at first." ${ }^{31}$ Indeed, it is hard to see how the reversed No of God in the relation of Creation with the reversed Yes of World, and the reversed Yes of God in the relation of Revelation with the reversed No of Human, can be viewed as the No and Yes specifically of God if the internal And is not retained. Arguments having the same structure equally apply to World and Human. From the perspective of supplementation as opposed to replacement, the unity of God's attributes is not broken in Creation and Revelation and then restored with Redemption. The unity in the primordial condition is actually retained, but since elements are still incomplete when isolated, retention of their unity does not guarantee stability. Only when the elements are linked by all three relations is the risk of their falling back into Nothing finally removed. This interpretation preserves the dependence of the elements on external relations that is so central to Rosenzweig's thought, while asserting that the internal unity of the attributes of the elements is also constitutive.

In this view of reversal as supplementation rather than replacement, not only is an element with its dual attributes fact, and a relation with its dual attributes also fact, but an attribute with its dual values is likewise fact. Each attribute is an And that unites its Yes and No values, this duality not being mismatch or inconsistency.

\subsection{Diachronic ascent}

The structure of the system changes as each relation is sequentially added to the elements. In graph theory the set of all possible structures for any system defines a "lattice of structures.” ${ }^{2}$ The lattice, applied to Rosenzweig's elements, is shown in Figure 12. The lattice spans the range from the multiplicity near the bottom of G:W:H, where God, World, and Human

\footnotetext{
${ }^{30}$ There is, however, a 'black box' or functionalist systems view in which an unknown internal order is indirectly specified by external relations. Also, in network analysis, only the external relations of nodes are considered. But these purely functional perspectives reflect either epistemological limitations or choices; systems theory does not endorse an ontology in which external relations alone are constitutive.

${ }^{31}$ Ernest Rubinstein, An Episode of Jewish Romanticism: Franz Rosenzweig's The Star of Redemption (New York: SUNY Press, 1999), 65.

${ }^{32}$ For discussion of this lattice, see Klaus Krippendorff, Information Theory: Structural Models for Qualitative Data (Beverly Hills: Sage, 1986).
} 
are isolated from one another, to the unity at the top of GWH, i.e., a triadic relation between God, World, and Human. In the notation here a colon “:” denotes “independent of” and the structure in which all the elements are separated by colons is referred to as the "independence model.” Below the independence model, G:W:H, there is an ultimate bottom consisting - if one has three elements - of a triad of Nothings, $\Phi: \Phi: \Phi,{ }^{33}$ (mathematically $\Phi$ is the "empty set”).

Figure 12. Ascent towards unity Structures in-between G:W:H (God:World:Human) and $\Phi: \Phi: \Phi$, indicated by ellipsis, are not shown. The relations of Creation, Revelation, and Redemption define the diachronic path shown with arrows.

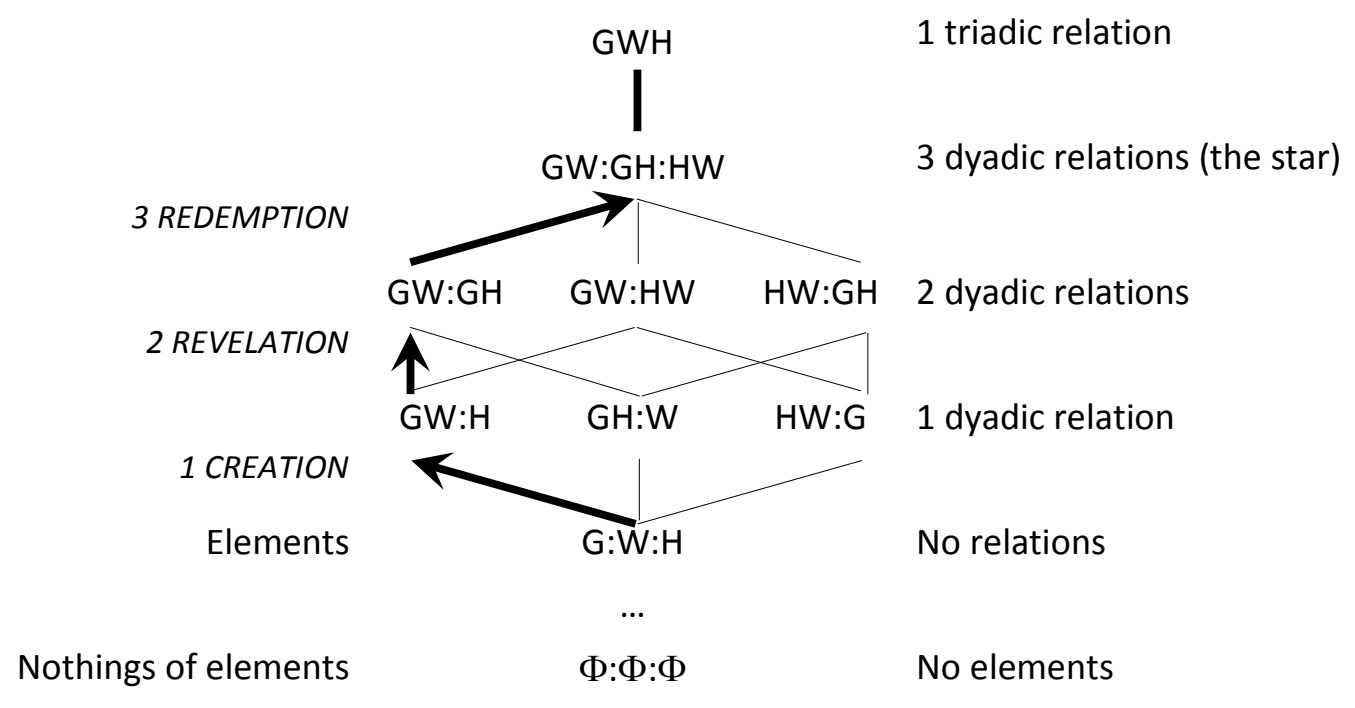

In the systems terminology of von Bertalanffy, ${ }^{34}$ ascent through the lattice is called "progressive systematization” and descent through the lattice is called "progressive segregation." Progressive systematization, also referred to as "composition," is integration from some initial multiplicity; progressive segregation, also referred to as "decomposition" is differentiation or disintegration from some initial unity. Both involve diachronic relations between a whole and its parts. Rosenzweig has been described as "engrossed in a part-whole problem." 35 The holism of Idealism is a doctrine of progressive segregation. Rosenzweig rejects this as "old thinking” and instead favors bottom-up progressive systematization.

The diachronics of the star, i.e., unification of the elements and generation of the All, is a particular path through the lattice, denoted in Figure 12 by bold arrows. The path begins with G:W:H, a structure that means that God, World, and Human, having emerged from their respective Nothings, are separate and unrelated. With Creation there is a transition to $\mathrm{GW}: \mathrm{H}$, where God and World are related but Human is still isolated. Revelation adds GH to give the structure GW:GH. So, in Revelation both God and Human are related and God and World and related, but there is no relationship yet between World and Human. Finally, Redemption adds the

\footnotetext{
${ }^{33}$ Moses (op cit, 56) writes, "We see that to the breaking of Being corresponds the shattering of nothingness." $\Phi: \Phi: \Phi$ is an apt mathematical metaphor for this shattering.

${ }^{34}$ Ludwig von Bertalanffy, Ludwig. General System Theory (New York: George Braziller, 1939).

${ }^{35}$ Louis P. Blond, “Franz Rosenzweig: Homelessness in Time.” New German Critique 111, 37 no.3, (2010): 27-33. DOI 10.1215/0094033X-2010-014.
} 
Human-World relation to yield the structure GW:GH:HW, which represents Rosenzweig's One and All. Insofar as the lattice indicates not only a particular diachronic path but all possible combinations of relations between the elements and all possible paths (possibilities that stand outside time), the lattice itself might be considered a view from "eternity."

Paths that do not correspond to Rosenzweig's sequence might also be given interpretations. In Rosenzweig's view, Revelation in mainstream Islam does not posit a God who loves individual human beings. Discussion of this controversial claim is beyond the scope of this article, but it can be understood as a claim that Islam ascends to GW:H but not to GW:GH. Indigenous religions might be viewed as lacking Revelation in Rosenzweig's sense, ascending only to GW:H or perhaps GW:HW; more fundamentally, from Rosenzweig's perspective, one might regard these religions as conflating God and World. Secular modernity might be viewed as positing only HW:G, or just HW, denying $\mathrm{G}$ altogether, thus constituting a dyadic rather than triadic ontology. For Rosenzweig, in Buddhism $G$ is demoted and thus Buddhism falls back into the Nothing - $\Phi: \Phi: \Phi$ in the lattice of structures - although from a Buddhist perspective, this is not a fall but enlightenment.

In Rosenzweig's path of Creation, Revelation, and Redemption shown with bold arrows in Figure 12, only the structure consisting of three dyads, GW:GH:HW, is immune to the danger of falling back into Nothing. Each element secures a kind of persistence in the face of its Nothing via its own Yes and No, united by an endogenous And. However, it is only through interaction with other elements that stability is gained. The hexadic structure of the Davidic star locks the elements God, World, and Human, and the relations Creation, Revelation, and Redemption together, and in doing so provides a framework of reciprocity that stabilizes each element through its relations with the other two.

That the star is resistant against falling back into Nothing is due to the fact that $\mathrm{GW}: \mathrm{GH}: \mathrm{HW}$ is cyclic, and the only cyclic structure in the lattice. It is interesting to note that in this systems theory framework the algorithm for detecting cyclicity is a test for the structure not being reducible to the empty set $(\Phi) .{ }^{36}$ In this algorithm, one deletes any element that (i) is found only in one relation or (ii) is redundant. Applied to GW:GH, for example, the algorithm transforms GW:GH into G:G by (i), since $\mathrm{W}$ and $\mathrm{H}$ are both involved in only one relation and are thus deleted; it then transforms $G: G$ into $G$ by (ii) since one $G$ is redundant, and it finally transforms $\mathrm{G}$ into $\Phi$ by (i) again. Thus, according to the algorithm, GW:GH reduces to the empty set, as do GW:HW and HW:GH, which also have only two dyadic relations. Only the cyclic structure, GW:GH:HW, with all three dyadic relations, resists this reduction to $\Phi$, i.e., to Nothing, because each element is involved in two relations, and is thus immune to deletion by (i) or (ii).

This algorithmic test for cyclicity is a mathematical metaphor for Rosenzweig's assertion that structures less complex than the star are vulnerable to regression back to Nothing. Rosenzweig used the differential calculus as a metaphor for something emerging from nothing, ${ }^{37}$

\footnotetext{
${ }^{36}$ Krippendorff, op cit.

${ }^{37}$ Mathew Handelman, “Franz Rosenzweig’s Modern Mathematics,” Leo Baeck Institute Year Book 57, no.1 (2012): 145-161. https://doi.org/10.1093/leobaeck/ybs010.
} 
but at the beginning of Part II, he writes, "[t]he symbolic language of mathematics we used above to explain the becoming of the elements fails here." 38 This may be so for the differential calculus, but graph theory is also a useful source of mathematical metaphors.

\section{Beyond the star}

\subsection{Triadic relation of the elements}

GW:GH:HW, which consists of three dyads, is not, however, the top of the lattice, its most integrated structure. Above it, as shown in Figure 12, is GWH, an inherently triadic relation involving God, World, and Human that not only encompasses but also exceeds the three dyadic relations of Creation, Revelation, and Redemption. The idea that a triadic relation is not in general equivalent to three dyadic relations is illustrated by the Borromean rings of Figure 13.

Figure 13. A non-decomposable triad

These three interlocked Borromean rings illustrate a triadic relation that is non-decomposable.

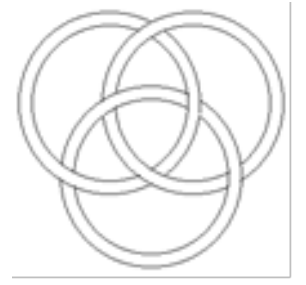

The three rings cannot be separated - one is reminded of the quote from Kohelet (Ecclesiastes) 4:12, “A triple stranded cord is not easily broken" - but if any ring is removed, the other two fall apart easily. This structure is a mathematical example of an inherently triadic relation that is not decomposable, i.e., is not simply a sum of three dyadic relations

A GWH triadic relation is actually implicit in Rosenzweig's account. In completion of the All with the relation of Redemption, in which Human acts on World, Redemption is experienced not only by World and Human, but also - and especially - by God. This means that Redemption is not simply a dyadic relation between Human and World, but a triadic relation that includes God. In Redemption, World and Human join in love of and thanks to God. In fact, the deepest significance of Redemption is not that World and Human redeem one another, but that in this process God is redeemed.

The same triadic character is also implicit in both Revelation and Creation. Revelation is the promise of Creation realized, and of Redemption anticipated. In Revelation, the face of God shines upon the human being, the ultimate effect of which is to transform World. As Mosès succinctly puts it, "[t]he function of man is precisely to transmit Revelation to the world." 39 Moreover, in Creation, God creates World, the full realization of which is the human being. Thus ultimately although not proximally Creation points towards Human, Revelation towards World, and Redemption towards God. Using the terminology of systems theory what is involved here is the distinction between "immediate effects" and "ultimate effects" 40 shown in Figure 14.

\footnotetext{
${ }^{38}$ Rosenzweig, 156.

${ }^{39}$ Mosès, p.135.

${ }^{40}$ W. Ross Ashby, An Introduction to Cybernetics (London: Chapman \& Hall Ltd., 1956).
} 
Figure 14 "Immediate effects" and "ultimate effects" of the three relations

The "immediate effects" of Creation, Revelation and Redemption are indicated with solid arrows. The "ultimate effects" are indicated with dashed arrows.
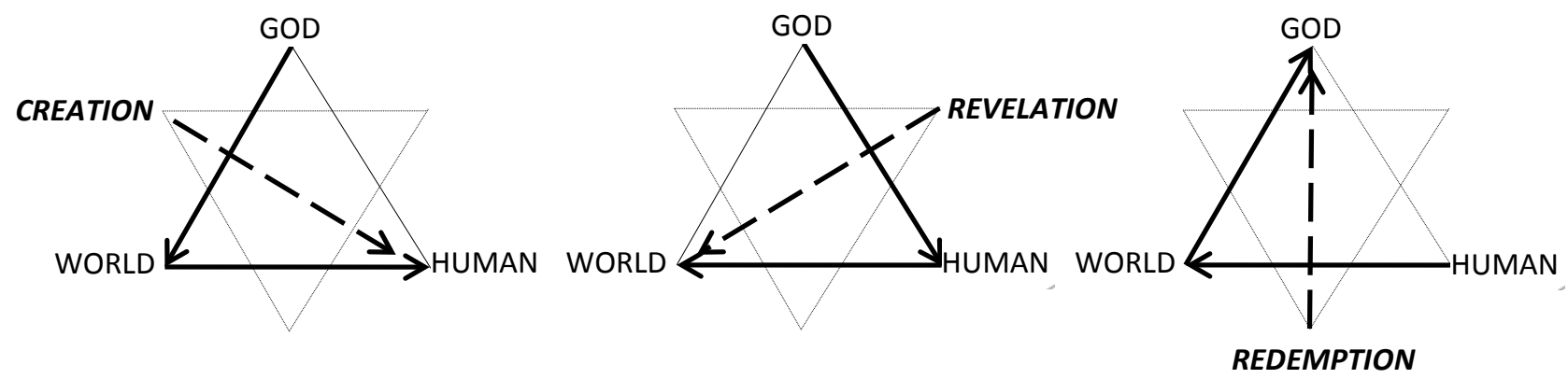

The element that each relation points towards is precisely the element that it ultimately unifies, as discussed earlier. ${ }^{41}$ In these complexities in Rosenzweig's account, there is evidence that he conceives of the All not merely as the sum of three dyadic relations, depicted by the star, but rather as the triadic relation, GWH.

\subsection{Inequality of the elements}

The discussion thus far has presumed the equality of the elements, insisted upon by Rosenzweig. But for Rosenzweig the elements are also not equal. This is shown in Figure 15 in three ways. Figure 15(a) is a modification of the triangle of three elements shown in Figure 1(a) and Figure 2(a). In the terminology of graph theory, these earlier representations of this triangle are undirected graphs which have 3-fold symmetry, suggesting equality of elements. In contrast, Figure 15(a) is a directed graph, where linkage directions indicate active-passive relationships between the elements. With directions added, the triangular symmetry is broken and thus the elements are no longer equal. God, the active element in both the God-World and God-Human relations, is privileged. Moreover, although the relationship between Human and World is reciprocal, there is directedness to it, at least in its initiation.

Figure 15 Inequality of the elements

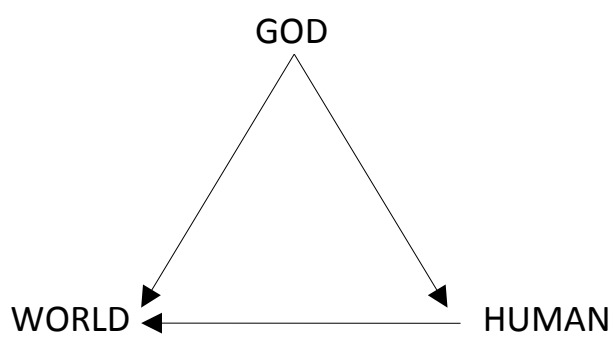

(a)

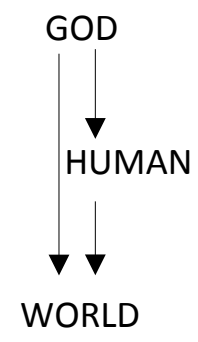

(b)

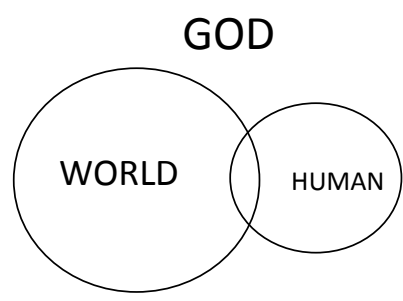

(c)

Figure 15(b) reorganizes Figure 15(a) spatially to highlight the role of Human as mediator between God and World, reflecting the centrality of the Human element. For Rosenzweig, Human mediation between God and World, when fully realized, brings Redemption. While Redemption is the relation between Human and World, in acting on World

\footnotetext{
${ }^{41}$ This was diagrammed in Figure 11 at the end of Section 3.1 Creation, Revelation, Redemption.
} 
the human being acts as God's agent, and is able to do so having been empowered in Revelation by God's love. ${ }^{42}$

In Figure 15(c), World partially contains Human since a human being is part of the natural order (in Rosenzweig's idiosyncratic algebraic notation, ${ }^{43}$ “ $\mathrm{A}=\mathrm{B}$ ”) and since the worldly neighbor whom we are enjoined to love is human. However, because for Rosenzweig Human as subjective Self (" $\mathrm{B}=\mathrm{B}$ ") is not subsumed by World, in the diagram the part of the small circle that does not overlap World is identified as the separate element, Human. Figure 15(c) shows God as outside of World and Human. God could be depicted in this diagram as a circle separate from the circles of World and Human, in keeping with the equality of the elements, or alternatively as a larger circle encompassing both World and Human in the sense that at "the End" or in eternity outside of time, God is indeed the All, encompassing World and Human.

So, while Rosenzweig asserts the equality of the elements, he also presents them as unequal. He insists on having it both ways. The inconsistency between equality and inequality is partially resolved by the distinction between synchronics and diachronics, and between how things appear to us in the present moment versus how they are ultimately. Synchronically, and from a human perspective, the All manifests as three equal elements. But diachronically, the All ends in God subsuming World and Human. In the words of the Alenu prayer, "In that day, God will be one, and his Name one." 44 More simply, one might say that for Rosenzweig incompleteness is a major concern, but inconsistency, i.e., the embracing of opposites, is not. Indeed, inconsistency, normally regarded as a flaw in philosophy, is a major source of the richness and power of the Star.

\subsection{The hidden tetrad}

The Star is saturated with number. It speaks of All and Nothing: the All that Idealism imagines already exists but is denied by Rosenzweig; the Nothing that is Rosenzweig's version of the Nothing that Hegel opposed to Being. The Star speaks about the One and the Many: the One implicit in the anticipated future unification of the All; the Many in the elements, relations, and triads that have yet to be unified. These archetypal "numbers" can be displayed in a tetrad of number (Figure 16), ${ }^{45}$ an invisible presence that frames the narrative of the Star.

\footnotetext{
${ }^{42}$ The hierarchy of Figure 15(b) is the same as the Chinese "Three Powers" scheme of Heaven-ManEarth, in which Man is the channel between Heaven and Earth.

${ }^{43}$ Rosenzweig, 97

${ }^{44}$ https://www.sefaria.org/Siddur_Edot HaMizrach\%2C Weekday Shacharit\%2C Alenu?ven=Sefaria C ommunity_Translation\&lang=bi. These words in the prayer are from Zechariah 14:9. Rosenzweig, 406, also cites them.

${ }^{45}$ The general idea of this tetrad (not the specific designation here of its four terms) derives from the "systematics" of John G. Bennett set out in his The Dramatic Universe: Volume Three: Man and His Nature (London: Hodder \& Stoughton, 1966). The systems theoretic character of Bennett's systematics and his notion of the tetrad is explored in Martin Zwick, “Ideas and Graphs,” International Journal of General Systems 47, No. 7, (2018): 731-750.
} 
Figure 16. A tetrad of number

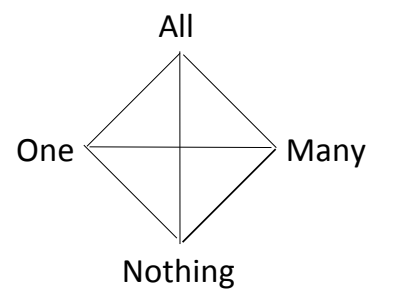

In the history of religious thought in Judaism, as well as in other religions and philosophical systems, each of these four "numbers" has been used to characterize God or the metaphysical equivalent of divinity. Nothing is God as ultimate ground, the Kabbalistic Ayin, Buddhist emptiness. All is God as infinite, the Kabbalistic Ayn Sof. One is God as unitary, the central tenet of monotheism avowed in the Shema, the Plotinian One. Many is God as the Kabbalistic Sefirot, the Christian Trinity, the Hindu gods and goddesses, the pagan pantheons.

Three interpretations of this tetrad are shown in Figure 17. In Figure 17(a), All and Nothing define a vertical axis, which brackets and is perpendicular to the horizontal axis, defined by One and Many. All and Nothing are complementary. In the traditional dyad of unity vs multiplicity, One and Many are also complementary.

Figure 17 Three forms of the tetrad of number

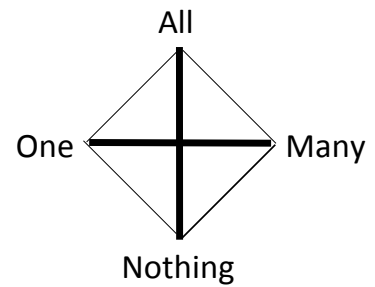

(a)

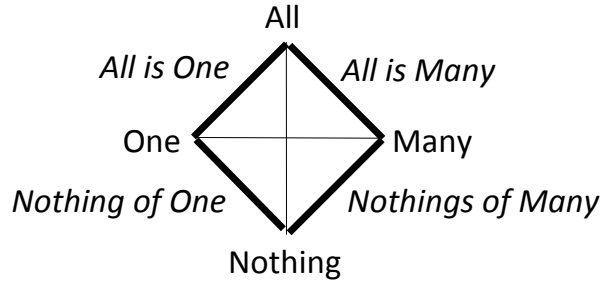

(b)

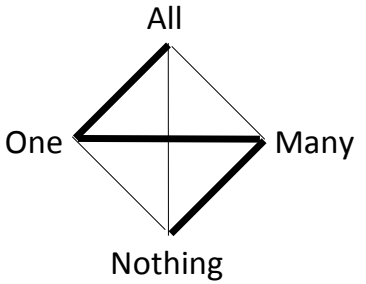

(c)

Figure 17(b) shows that in bracketing One and Many, All partakes in both, as does Nothing. All has the dual character of being both One and Many simultaneously: there is only one All but it includes everything. As Pollock writes, "the word 'All' can imply both multiplicity - and indeed, the most wide-ranging multiplicity possible - and unity; it includes all beings, but it is something singular: it is 'the All.", 46 Nothing likewise has this dual character, being related to One and Many simultaneously. In binary logic and mathematics, Nothing (zero) is the complement of One. Nothing is also the complement of Many in two senses. In the first sense, Nothing is an inexhaustible matrix of many possible arisings. The void not as empty but as full in potential - has a long history in philosophical and religious thought and has contemporary scientific endorsement by quantum physics. Since potential is no less real than actual, Nothing here is "a determinate nothing rather than a nothing conceived as absolute." ${ }^{47}$ In the second sense, each element within the Many has its own Nothing.

\footnotetext{
${ }^{46}$ Pollock, 24.

${ }^{47}$ Benjamin Pollock, "Franz Rosenzweig,” in Stanford Encyclopedia of Philosophy, 2009b. http://plato.stanford.edu/archives/fall2009/entries/rosenzweig/. (This is the only reference to this Pollock encyclopedia article; all other references in this article to Pollock refer to 2009a.) Paul Tillich, Systematic
} 
In Figure 17(b), passage on the right side of the tetrad from Nothing to Many might be seen as negation (the many particulars are the No of World), while passage on the left side from Nothing to One might be seen as affirmation (the one logos is the Yes of World). A similar duality applies to All: Many is the No and One is the Yes of All. Descending the left side of Figure 17(b) is progressive segregation, which includes All, One, and Nothing, and is the orientation of Idealism that Rosenzweig rejects. Ascending the right side of Figure 17(b) is progressive systematization, which includes Nothing, Many, and All, and is the orientation that Rosenzweig favors.

The third form of the tetrad of number, shown in Figure 17(c), is an ascending hierarchy from Nothing to Many to One to All. This is related to the lattice of structures of Figure 12. Nothing is the bottom of the lattice, $\Phi: \Phi: \Phi$, actually, as Rosenzweig insisted, a multiplicity of Nothings. Many extends from the G:W:H up to GW:H and GW:GW, the results of Creation and Revelation. Finally after Redemption, GW:GH:HW, or perhaps GWH, is Rosenzweig's One and All. The Many-One-All sequence appears in a diary entry by Rosenzweig, quoted by Pollock, as follows: "According to the Hegelian scheme, the line Kant-Fichte-Hegel lets itself be grasped as multiplicity-unity-allhood. In Kant, the pure 'empirical' multiplicity...by Fichte, the pure 'theoretical' unity...by Hegel ... the Allhood grounded on pure intuition.”48

\section{Knowledge of the All}

\subsection{Thought, experience, intuition}

Rosenzweig recognizes that experiencing Creation, Revelation, and Redemption, which is the subject of Part II of the Star, still does not afford a grasp of the highest unity of the All. As Pollock explains, "Rosenzweig suggests that if the systematic unification [emphasis added] of particular beings [the elements] can be known through the discursive method of the reversals into relations, the unity [emphasis in the original] of the system can only be grasped in its immediacy through an act of vision or intuition." 49 In terms of the lattice of structures, unification is at the level of GW:GH:HW; unity is at the level of GWH. In Part III of the Star, Rosenzweig describes this intuition as mystical, as a third kind of knowledge made possible by the preceding nonmystical labor of thought (Part I) and experience (Part II). Pollock asks "how ... [thought, experience, intuition] are...conceivable in their unity." He answers that intuition (vision) is the And that integrates thought and experience. This is represented in Figure $18 .^{50}$

Figure 18. Thought and experience as Sache and Tat

Thought is substance; experience is act; intuition unites the two.

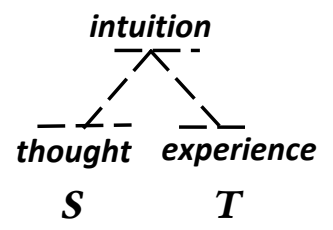

Theology (Chicago: University of Chicago Press, 1967), referred to the alternative relative and absolute senses of "nothing” with the Greek terms me on and ouk on, respectively.

${ }^{48}$ Pollock, 272.

${ }^{49}$ Pollock, 228.

${ }^{50}$ Pollock, 255, 268. 
The three stages of ascent to knowledge of the All - thought, experience, and intuition are summarized in Table $1 .^{51}$ There is yet another transformation. As shown in Table 1, GWH becomes $\mathrm{G}$ - the All is simply God. Rosenzweig writes, “[i]n the Redemption, that of the world through man and that of man through the world, God gives himself his own Redemption. Man and the world fade out in Redemption, God completes himself." ${ }^{2}$ Although this unitary - and solitary - God, as opposed to the God that is equal to other elements, transcends human knowledge, Rosenzweig in this passage still speaks of it.

Table 1. Stages of knowledge of the All

Knowledge of the All is gained via thought, then experience, then intuition.

\begin{tabular}{cll} 
G & & The Star \\
\hline GWH & intuition & Part III \\
\hline GW:GH:HW & experience & Part II \\
\hline G:W:H & thought & Part I \\
\hline
\end{tabular}

$\Phi: \Phi: \Phi$

\subsection{Present, past, and future}

While Rosenzweig accords equal status to God, World, and Human, his primary orientation is Human-centered. Creation, Revelation, and Redemption align with the human experience of past, present, and future. This can be illustrated using a double cone diagram, where the vertical structure-function diagram introduced earlier, ${ }^{53}$ repeated below in Figure 19(a), is rotated clockwise by 90 degrees, yielding the horizontal past-future diagram of Figure 19(b). In this temporal version of the double cone diagram, the present moment is the focal point that binds past and future together. The concentration of past events (the converging cone on the left) launches the expansion of future events (the diverging cone on the right). Creation is the past, which has left the residue of substance, Sache; Redemption is the future, a call to act, Tat. Revelation links Creation and Redemption, and fuses substance and act into a diachronic process which is fact, Tatsache.

Figure 19. Human-centered diachronics

This Human-centric view is "from the middle," i.e., from the present moment.

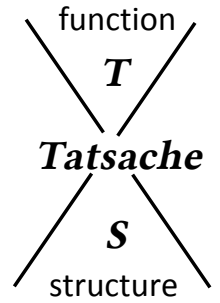

(a)

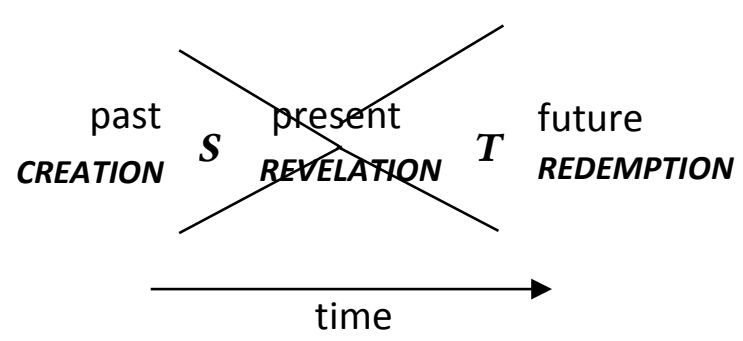

(b)

\footnotetext{
${ }^{51}$ Rosenzweig's third stage is reminiscent of Spinoza's third kind of knowledge, which is also intuitive and requires the labor of Spinoza's second kind of knowledge, which resembles Rosenzweig's first stage. Baruch Spinoza, Ethics, trans. A. Boyle (New York: Dutton, 1967).

${ }^{52}$ Rosenzweig, 256.

${ }^{53}$ Figure 5(c) in Section 2.2 Attributes.
} 
Past and future are experienced, not merely grasped in thought. Creation is the past we experience in substance, that which is always already here. Redemption is the future that is not yet, which we experience in anticipation and responsibility. Revelation is the experience of the love of God that affirms our being, and empowers us to redeem what has been created.

Revelation is thus an And that binds together Creation and Redemption. The idea that a relation can link not only elements but also relations has been presented above, and that earlier discussion showed Revelation linking Creation and Redemption as $\boldsymbol{T a t}$ and $\boldsymbol{S a c h e}$, respectively. ${ }^{54}$ In the human-centered diachronics of Figure 19, however, the Sache-Tat assignments of these relata are reversed, because of the correlation of contraction with Yes and expansion with No. These different polarity assignments are contrasted in Figure 20.

Figure 20. Alternative polarities of Creation and Redemption as the relata of Revelation

(a) Polarities of these relata in the star as depicted in Figure 10(b).

(b) Polarities of these relata in the human-centered diachronics as depicted in Figure 19(b).

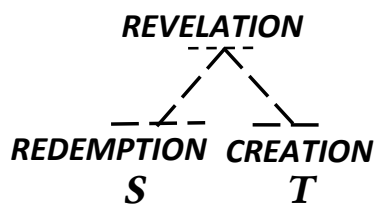

(a)

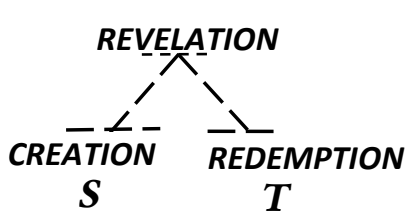

(b)

From the perspective of the present, the past and the future are in a sense equally original, but the arrow of time breaks this symmetry, and makes the No (Tat) of the future presuppose the Yes (Sache) of the past. The temporal scheme diagrammed in Figure 19(b) derives ultimately from Schelling, but in Schelling, the past is No and the future Yes. Bielik-Robson notes that Yes and No are seen in opposite ways by Schelling and Rosenzweig. ${ }^{55}$ For Schelling, contraction is No and expansion Yes. For Rosenzweig, in the emergence of the elements from their Nothings, and in the experience of past and future, contraction is Yes and expansion No.

\section{Discussion and summary}

Many of Rosenzweig's ideas are readily expressed with systems theoretic concepts and diagrams. Diagrams are polymorphic, as exhibited by the variations of structure explored in this article. They are synergistic with words, as is becoming more appreciated in the growing understanding of the significance of diagrams in Kabbalah. A diagram is itself pure structure. It can distill and represent the essence of an idea. ${ }^{56}$ In fact, as music proves, structure by itself without elaboration in words can convey meaning. The diagrams offered in this article depict the exoskeleton that structures Parts I and II of the Star. ${ }^{57}$ One might analogize this skeletal structure to the underlying constraints that confer form upon a poem. Syntactic constraint is inseparable from semantic meaning, so grasping the form of a poem, or of any literary, philosophical, or religious writing, increases - and alters - our understanding of its content.

\footnotetext{
${ }^{54}$ Figure 10(b) in Section 3.1 Creation, Revelation, Redemption.

${ }^{55}$ Agata Bielik-Robson, “The 'And' in Franz Rosenzweig’s Work: Connection, Disjunction, Contrariety.” Archivio Di Filosofia lxxxvi 1 (2018): 123-132. https://doi.org/10.19272/201808501013.

${ }^{56}$ Zwick, 2018.

${ }^{57}$ Part III of the Star is only touched on very briefly in section 5.1 .
} 
Of course there is a great deal more to the Star than ideas that are systems theoretic or amenable to diagrams. The interpretation offered in this article demonstrates the relevance of systems ideas and the usefulness of diagrams for understanding the Star, and thus potentially also other works in philosophy and religion. To be sure, this interpretation is intended only as a supplement to and not a replacement for other interpretations.

The parallels between systems theory and Rosenzweig's thought even include an ambiguity common to both. There is a basic question about the Star: Is it epistemology or ontology, a human-centered view or a view from the Absolute, about human knowledge of the All or about the All as such? On the one hand, the primordial condition in which God, World, and Human are equal, and equally original, seems best understood as epistemology, not ontology. On the other hand, the statement " $[\mathrm{m}]$ an and the world fade out in Redemption, God completes himself" 58 sounds like ontology. The Star seems to embrace both, perhaps unavoidably since ontology and epistemology are necessarily entangled. This ambiguity also afflicts the notion of "system" which exhibits the same neutrality between ontology and epistemology that "being" does in philosophical discourse. In systems theory viewed as ontology, the world consists of systems; in systems theory viewed as epistemology, "system" is in the eyes of the beholder and is just another name for "model."

The Star embodies many mathematical ideas that are central to systems theory. "Language can reach God because it stems from God," 59 but mathematics also can reach God because the logos by which God grounds World in Creation is mathematical, at least according to Pythagoras, Newton, and Einstein. One might argue that mathematics is to World as language is to Human. The fact that in Genesis Creation occurs through language attests only to the Talmudic adage that the Torah speaks in the language of human beings. God communicates not only via scripture but also via the book of nature. This said, language has priority because it is closer to us than mathematics; while mathematics and diagrams augment words, words do penetrate deeper.

The interpretation of the Star offered in this article argues that the elements in their primordial state are incomplete because their attributes are only potential, the incompleteness being remedied by entry into external relations ${ }^{60}$ which supplement but do not replace the internal and primordial unity of these elements. Incompleteness is a major theme in the Star. Mosès notes that "incompleteness is, for Rosenzweig, the very essence of time," ${ }^{\prime \prime}$ and this view is in full accord with the fundamental systems idea that "incompleteness in being engenders becoming.” ${ }^{2}$ Incompleteness reaches its greatest intensity in the wait for, and the urgency of, Redemption. Until then, World, Human, and God remain unfinished. ${ }^{63}$

\footnotetext{
${ }^{58}$ Rosenzweig, 256.

${ }^{59}$ Mosès, 290.

${ }^{60}$ This contrasts with the assertion of Bielik-Robson, ibid, that "[i]n Rosenzweig's modification of the Schellingian method of narration, the beginning no longer poses a problem which the future development is supposed to solve, sublate, heal, or appease.”

${ }^{61}$ Mosès, 136.

${ }^{62}$ Zwick, 1984. From a systems perspective, inconsistency in being also engenders becoming. For example, Gregory Bateson, Mind and Nature: A Necessary Unity (New York: Bantam Books, 1979), 58-
} 
Rosenzweig's final words in the Star are a response to the universal condition of being unfinished. Implicit in his sending us back "INTO LIFE" ${ }^{64}$ is the commandment that follows from incompleteness, namely the call to responsibility and tikkun that is succinctly expressed in Pirké Avot: "You are not required to complete the work, but you are not free to abandon it."65 66

59, shows how contradiction temporally unfolds in cyclicity. For Schelling diachronics is driven by inconsistency, but for Rosenzweig it is driven by incompleteness.

${ }^{63}$ Moses, 282, also writes that "everything appearing in historical reality will by definition appear to Judaism as marked by incompleteness.”

${ }^{64}$ Rosenzweig, 447.

${ }^{65}$ Pirké Avot. Wisdom of the Jewish Sages, trans. Rabbi Chaim Stern (Hoboken New Jersey: Ktav Publishing House, 1997), 2:16, 74.

${ }^{66}$ This article draws heavily on Pollock (2009a), which inspired this study, and secondarily on Mosès (1992). I thank Shane Dicks for urging me to consider interpretations of paths up the lattice of structures other than the path associated with the sequence Creation, Revelation, and Redemption. I'm grateful for the valuable copy editing suggestions of Miri Fenton, who is of course not responsible for the infelicities of logic and style that remain in the text. 